\title{
Towards Establishing a Touchless Gesture Dictionary based on User Participatory Design
}

\author{
Haewon Song ${ }^{1}$, Huhn Kim ${ }^{2}$ \\ ${ }^{1}$ Graduate School of NID Fusion Technology, Seoul National University of Science and Technology, Seoul, 139-743 \\ ${ }^{2}$ Department of Mechanical System Design Engineering, Seoul National University of Science and \\ Technology, Seoul, 139-743
}

\begin{abstract}
Objective: The aim of this study is to investigate users' intuitive stereotypes on non-touch gestures and establish the gesture dictionary that can be applied to gesture-based interaction designs. Background: Recently, the interaction based on non-touch gestures is emerging as an alternative for natural interactions between human and systems. However, in order for non-touch gestures to become a universe interaction method, the studies on what kinds of gestures are intuitive and effective should be prerequisite. Method: In this study, as applicable domains of non-touch gestures, four devices(i.e. TV, Audio, Computer, Car Navigation) and sixteen basic operations(i.e. power on/off, previous/next page, volume up/down, list up/down, zoom in/out, play, cancel, delete, search, mute, save) were drawn from both focus group interview and survey. Then, a user participatory design was performed. The participants were requested to design three gestures suitable to each operation in the devices, and they evaluated intuitiveness, memorability, convenience, and satisfaction of their derived gestures. Through the participatory design, agreement scores, frequencies and planning times of each distinguished gesture were measured. Results: The derived gestures were not different in terms of four devices. However, diverse but common gestures were derived in terms of kinds of operations. In special, manipulative gestures were suitable for all kinds of operations. On the contrary, semantic or descriptive gestures were proper to one-shot operations like power on/off, play, cancel or search. Conclusion: The touchless gesture dictionary was established by mapping intuitive and valuable gestures onto each operation. Application: The dictionary can be applied to interaction designs based on non-touch gestures. Moreover, it will be used as a basic reference for standardizing non-touch gestures.
\end{abstract}

Keywords: Touchless or Non-touch gestures, Gesture dictionary, Stereotypes, Mental models, Intuitiveness

\section{Introduction}

급격한 기술의 발달과 함께 컴퓨터, TV, 스마트폰을 둘러 싼 디지털 미디어 환경이 변화함에 따라 사람들의 명령을 기기에 입력하고 처리하는 상호작용 방식에도 많은 변화가 일어나고 있다. 마우스와 키보드, 리모컨의 입력방식은 인간
과 컴퓨터간의 소통을 위해 인공적으로 만들어졌다는 점 때 문에 그 사용성에 있어 한계를 가지고 있다. 이러한 한계를 극복하고자 음성이나 제스처를 활용한 보다 자연스러운 인 터페이스(Natural User Interface, NUI) 개발에 많은 연구 가 집중되고 있다(Hummels \& Stapers, 1998). 그 중에서 도 비접촉 제스처(이하. 제스처)가 직관적이며 자연스러운 인터랙션을 위한 하나의 대안으로 최근 부각되고 있다.

Corresponding Author: Huhn Kim. Department of Mechanical System Design Engineering, Seoul National University of Science and Technology, Seoul, $139-743$. Mobile: +82-10-9111-5766, E-mail: huhnkim@seoultech.ac.kr Copyright@2012 by Ergonomics Society of Korea(pISSN:1229-1684 eISSN:2093-8462). All right reserved.

(c) This is an open-access article distributed under the terms of the Creative Commons Attribution Non-Commercial License(http://creativecommons.org/licenses/by-nc/3.0/), which permits unrestricted non-commercial use, distribution, and reproduction in any medium, provided the original work is properly cited. http://www.esk.or.kr 
제스처에 대한 연구는 게임산업 및 의료산업분야 등에서 진행되어 왔으며, 최근에는 로봇산업을 비롯하여 $\mathrm{TV}$, 휴대 폰, 프로젝터 등 다양한 제품과 시스템에 적용 및 관련 연 구가 진행되고 있다. 이처럼 다양한 분야에서 연구가 활발 히 진행 중에 있으나 주로 제스처 인식기술들(e.g., vision technologies, data glove, etc.)에 연구가 집중되어, 이들 기술을 이용한 프로토타입을 개발하여 손과 몸을 이용하여 커튼이나 스마트 홈 환경 시스템을 조작하는 등의 기술적 인 부분에 초점을 맞춰 연구가 진행되고 있다(Kim, 2006, 2007). 하지만 제스처에 기반한 인터랙션이 보편적인 인터 페이스가 되기 위해서는 어떤 제스처가 사용자들에게 직관 적이며 사용하기에 편리한지와 같은 제스처 자체에 대한 본 질적인 연구가 필요하다. 그러나 사용자 제스처의 본질에 대 한 기존 연구들은 주로 기본적인 심볼형태의 제스처만을 대 상으로 실험실 수준에서 테스트 하여, 실제 사용자를 대상으 로 한 응용 어플리케이션 수준으로 가기에는 매우 연구가 부족한 상황이다. 특히, 사용자가 자연스럽게 자주 사용하는 제스처의 형태에 대한 연구들(Karam \& Schraefel, 2005; Epps et al., 2006; Stößel, 2009; Stößel \& Blessing, 2010) 이 있으나 이는 도메인과 문화, 연령, 제스처에 대한 친숙함 에 따라 달라질 수 있으므로 우리나라 사용자들을 대상으로 그대로 활용하기에는 무리가 있다. 국내에서는 Kim et al. (2007)이 디지털 TV의 직관적 조작을 위한 지시 제스처에 대한 연구를 수행하였다. 디지털 TV의 필수 기능을 바탕으 로 인터랙션 전문가 20명을 대상으로 다양한 지시 제스처들 을 추출하였으며, 이를 일반인들에게 설문조사를 실시하여 기능에 적합한 지시동작과 직관적 이해도가 높은 제스처를 선정하도록 하였다. 하지만 진정한 사용자 중심의 직관적인 제스처를 도출하기 위해서는 전문가에 의해 제스처 세트가 정의되는 방법에서 벗어나 Nielsen et al. (2004)의 연구에서 와 같이 사용자들의 머리 속 스테레오타입(Stereotype) 제 스처를 조사를 통해 알아내야 한다. Morris et al.(2010)에 의해 수행된 연구 결과를 보면, 사용자들은 소수 몇 명의 디 자이너에 의해 만들어진 제스처 보다 많은 사람들에 의해 만 들어진 제스처를 선호한다는 것을 알 수 있다.

따라서 본 연구에서는 보다 사용자에게 직관적이고 효과 적인 제스처가 무엇인지를 알아내기 위하여 사용자가 직접 참여하여 대표적인 기능 조작에 적합한 제스처를 만들어내 는 사용자 참여디자인(Participatory design)의 방법론을 활용하였다(Nielsen et al., 2004; Helman et al., 2008; Kray et al., 2010; Morris et al., 2010; Jaime et al., 2011). 특히 기존 연구들이 특정 하나의 도메인에서만 수행된 한 계가 있었기 때문에 도메인의 차이에 따른 사용 제스처의 차이를 살펴볼 필요성이 있다. 따라서, 본 연구에서는 서로 다른 네 종류의 기기를 대상으로 같은 조건에서 제스처 실
험을 수행하였다. 기기 별 단위조작 명령에 대해 참여자들 이 디자인한 제스처의 공통성 및 다양성을 살펴보기 위하여 Agreement score(의견일치도) 란 척도를 활용하였으며, 각 제스처의 빈도수 $(\%)$ 를 분석하였다. 또한 사용자 참여디자인 동안 참여자들은 본인이 디자인한 각 제스처에 대해 얼마나 제스처가 떠오르기 쉬운지(직관성), 얼마나 기억하기 쉬운지 (학습성), 얼마나 동작하기 편리한지(동작편의성), 그리고 얼마나 만족하는지(만족도)를 평가하였다. 더불어 제스처를 디자인하는데 걸린 시간을 측정하여 참여자들이 얼마나 쉽 게 제스처를 떠올리는지를 알아보았다. 본 연구에서는 이러 한 데이터들을 기반으로 스테레오타입 제스처를 도출하여 조작 별 적용 가능한 제스처들에 대한 어휘사전을 정립하였 다. 기존 연구들을 보면 스테레오타입으로 많이 등장하는 제 스처가 있음에도 불구하고 공통적인 조작에 대한 제스처 표 준화는 아직 이루어지지 않은 상황이다. 본 연구를 통해 정 립된 공통 기본 조작들에 대한 적용 가능한 제스처 어휘사 전은 제스처 인터랙션의 설계 및 향후 제스처 표준화를 위 한 기초자료로 활용할 수 있을 것으로 기대된다.

\section{Method}

\subsection{Choosing representative devices and operations}

먼저, 비접촉 제스처가 적용 가능한 대표적인 기기 및 조 작을 선정하기 위해서 FGI(Focus Group Interview)와 설 문조사를 실시하였다. FGI를 통해 비접촉 제스처 조작의 활 용 가능성과 가치를 심층적으로 탐색하고, 설문지 조사를 통 해 구체적인 기기와 단위 조작(예. 저장, 삭제 등)을 선정하 였다. FGI는 서울과학기술대학교 4학년 학부생 6 명을 대상 으로 약 1 시간 30 분 동안 진행하였으며, 참여자들은 동작 인식 게임 (ex. Nintendo Wii, Xbox Kinect)을 사용해 본적 있거나 제스처를 활용한 기기 조작에 관심 있는 학생들로 구 성하였다. 설문조사는 비접촉 제스처가 적용되었으면 하는 기기와 그에 대한 단위조작명령을 묻는 설문지를 작성하여 응답자 56명을 대상으로 실시하였다. FGI와 설문조사 결과, TV, Computer, Audio 그리고 Car Navigation이 대표 기기 로 선정되었다. 단위 조작은 Stößel \& Blessing(2010)의 연구에 사용된 34 개의 단위 조작을 기반으로 FGI와 설문조 사 결과 가장 자주 사용하며 기기들에 공통적이면서 기본적 인 것들을 대표 조작으로 선정하였다. Table 1은 최종 선정 된 기기들과 그에 해당하는 단위조작들을 보여준다. 체크표 시 $(\sqrt{ })$ 가 없는 빈칸은 해당 기기에는 그 조작이 없어 본 실 험에서는 제외하였다. 
Table 1. Representative devices and operations

\begin{tabular}{|c|c|c|c|c|}
\hline Operations & TV & Audio & Computer & Navigation \\
\hline Power on/off & $\sqrt{ }$ & $\sqrt{ }$ & $\sqrt{ }$ & $\sqrt{ }$ \\
\hline Previous/next page & $\sqrt{ }$ & $\sqrt{ }$ & $\sqrt{ }$ & \\
\hline Volume up/down & $\sqrt{ }$ & $\sqrt{ }$ & $\sqrt{ }$ & $\sqrt{ }$ \\
\hline List up/down & $\sqrt{ }$ & $\sqrt{ }$ & $\sqrt{ }$ & $\sqrt{ }$ \\
\hline Zoom in/out & & & $\sqrt{ }$ & $\sqrt{ }$ \\
\hline Play & $\sqrt{ }$ & $\sqrt{ }$ & $\sqrt{ }$ & $\sqrt{ }$ \\
\hline Cancel & $\sqrt{ }$ & $\sqrt{ }$ & $\sqrt{ }$ & $\sqrt{ }$ \\
\hline Delete & $\sqrt{ }$ & $\sqrt{ }$ & $\sqrt{ }$ & $\sqrt{ }$ \\
\hline Search & $\sqrt{ }$ & $\sqrt{ }$ & $\sqrt{ }$ & $\sqrt{ }$ \\
\hline Mute & $\sqrt{ }$ & $\sqrt{ }$ & $\sqrt{ }$ & $\sqrt{ }$ \\
\hline Save & $\sqrt{ }$ & $\sqrt{ }$ & $\sqrt{ }$ & $\sqrt{ }$ \\
\hline
\end{tabular}

\subsection{Experimental design}

앞서 선정된 네 종류의 기기 및 단위조작들에 대하여 서울 과기대 20 30대 남녀 20명씩 총 40명(평균 25.57세)을 대상으로 비접촉 제스처에 대한 사용자 참여디자인을 수행 하였다. 참여자들은 10 명씩 균등하게 네 종류 기기의 제스 처 디자인 작업에 할당되었다. 특히 참여자마다 디자인할 단 위 조작을 랜덤한 순서로 제시하여 순서에 따른 학습효과 (Order effects)를 배제시켰다.

\subsection{Experimental procedure}

사용자 참여디자인의 절차는 다음과 같았다. 먼저 참여자 에게 사전조사서를 작성하게 한 후 실험에 대한 간단한 안 내와 함께 실험을 시작하였다. 참여자에게는 어떤 기기인지 에 대한 정보만 알려줄 뿐 인터페이스에 대한 어떤 구체적인 정보나 이미지도 제공하지 않았다. 즉, 오직 본인들의 기존 지식과 경험에 기반하여 상상을 통하여 제스처를 디자인하 도록 하였다. 참여자들은 각 단위 조작에 가장 적합하다고 생각되는 3 개씩의 제스처를 자유롭게 취한 후, 취한 제스처 들에 대한 주관적 평가를 실시하였다. 참여자가 취한 제스처 는 추후 분석을 위해 비디오로 기록되었다. 주관적 평가는 제스처가 얼마나 직관적인지(직관성), 얼마나 기억하기 쉬운 지(기억용이성), 얼마나 동작하기 편한지(동작편의성), 얼마 나 만족스러운지(만족도)를 5점 척도로 평가하였다. 주관적 평가 후 각 제스처를 취한 이유에 대해 간략하게 인터뷰를 실시하였다. 이러한 과정을 기기에 따라 14 개(TV, Audio, Navigation) 혹은 16 개(Computer)의 단위 조작에 대하여 랜덤한 순서로 수행하였다.

\section{Results}

\subsection{Agreement score}

기기당 10 명씩의 참여자가 각 단위 조작에 대하여 3 가지 씩의 제스처를 취했으므로, 기기 별로 총 420개(=14조작 $\times 3$ 제스처 $\times 10$ 명 $)($ Computer는 480개)의 제스처가 도출 된다. 이렇게 도출된 제스처들을 유사도에 따라 그룹핑한 후, 서로 다른 제스처들이 참여자들의 얼마나 일치된 의견 으로 나온 것인지를 보기 위해 Agreement score(의견일 치도)를 척도로 활용하였다(Wobbrock et al., 2009; Lee et al., 2010). Agreement score의 계산 식은 아래 (3.1)과 같다. $\mathrm{N}$ 은 도출된 총 제스처의 수, $\mathrm{Ni}$ 는 $\mathrm{i}$ 형태의 제스처 개 수 $(\mathrm{i}=1 \cdots \mathrm{n})$ 를 나타낸다.

$$
A=\sum_{i=1}^{n}\left(\frac{N_{i}}{N}\right)^{2}
$$

예를 들어, 한 조작에 대하여 참여자들이 취한 제스처를 동일한 형태별로 그룹핑한 결과, 그룹 당 제스처의 개수가 8 개, 5 개, 5 개, 4 개, 3 개, 3 개, 2 개 (총 30 개) 였다면 그 조작 제스처의 Agreement score는 $(8 / 30)^{2}+(5 / 30)^{2}+(5 /$ $30)^{2}+(4 / 30)^{2}+(3 / 30)^{2}+(3 / 30)^{2}+(2 / 20)^{2}=0.169$ 로 계산된다. 반면, 만약 동일 제스처가 18 개, 10 개, 7 개, 3 개, 2 개 (총 30개) 였다면, $(18 / 30)^{2}+(10 / 30)^{2}+(7 / 30)^{2}$ $+(3 / 30)^{2}+(2 / 20)^{2}=0.540$ 의 Agreement score 값이 나온다. 즉, 하나의 단위 조작에 대한 Agreement score 값은 1 에 가까울수록 동일한 제스처가 더 많이 나왔음을, 0 에 가까울수록 다양한 제스처가 도출되었음을 의미한다.

기기 별 조작들의 Agreement score를 계산한 결과는 Table 2와 같았다. Agreement score의 전체 평균은 0.228 이었는데, 이를 기준으로 했을 때 기기와는 관계없이 단위 조작에 따른 차이를 볼 수 있었다. 즉, Previous/next page, Volume up/down, Zoom in/out에서는 Agreement score 가 평균 이상의 값을 가진 반면, Power on/off, List up/ down, Play, Cancel, Delete, Search, Mute, Save의 단위 조작에서는 평균 이하의 값을 가졌다. 이는 평균값 이상을 가지는 단위 조작들은 비교적 공통적인 제스처가 많이 도출 되었으며, 평균 이하의 값을 가지는 단위 조작에서는 비교적 제스처가 다양하게 도출되었음을 의미한다. 특히, Previous/ next page는 기기 별 Agreement score 값에 차이가 많은 것을 볼 수 있는데, TV와 Audio는 5개 이상의 다양한 제스 처가 나타난 것에 비해 Computer에서는 3개의 제스처로 비 교적 적은 제스처만 나타났기 때문이다. 
Table 2. Agreement scores on the operations for each device

\begin{tabular}{|c|c|c|c|c|}
\hline Operations & TV & Audio & Computer & Navigation \\
\hline Power on & 0.129 & 0.104 & 0.122 & 0.111 \\
\hline Power off & 0.122 & 0.113 & 0.116 & 0.102 \\
\hline Previous page & 0.280 & 0.351 & 0.413 & No d \\
\hline Next page & 0.278 & 0.351 & 0.442 & No data \\
\hline Volume up & 0.347 & 0.262 & 0.296 & 0.278 \\
\hline Volume down & 0.351 & 0.291 & 0.296 & 0.251 \\
\hline List up & 0.153 & 0.187 & 0.251 & 0.244 \\
\hline List down & 0.160 & 0.187 & 0.251 & 0.244 \\
\hline Zoom out & \multirow{2}{*}{\multicolumn{2}{|c|}{ No data }} & 0.422 & 0.320 \\
\hline Zoom in & & & 0.422 & 0.320 \\
\hline Play & 0.189 & 0.111 & 0.153 & 0.138 \\
\hline Cancel & 0.169 & 0.224 & 0.122 & 0.147 \\
\hline Delete & 0.222 & 0.207 & 0.187 & 0.140 \\
\hline Search & 0.129 & 0.220 & 0.151 & 0.138 \\
\hline Mute & 0.158 & 0.211 & 0.156 & 0.138 \\
\hline Save & 0.133 & 0.180 & 0.098 & 0.104 \\
\hline
\end{tabular}

\subsection{Frequency of derived gestures}

Agreement score가 높았던 단위 조작들을 중심으로 제 스처 빈도를 살펴보면 다음과 같다(도출된 모든 제스처 유 형에 대한 결과는 Song(2012)를 참고). Previous/next page 조작에 대해서는 모든 기기에서 화면전환을 위해 "검 지손가락으로 왼쪽 또는 오른쪽을 지시"하는 제스처의 빈도 가 가장 높았다. 참여자들은 이전 페이지로 전환하기 위해서 는 검지손가락을 왼쪽으로 가리키고(평균 $52.2 \%$ ), 다음 페 이지로 전환하기 위해서는 오른쪽으로 손가락을 가리켰다 (평균 53.3\%). 이외에도 책장을 넘기거나 스마트폰에서 화 면을 넘기는 제스처 형태로 "손을 오른쪽으로 이동하거나 또 는 왼쪽으로 이동"하는 제스처도 볼 수 있었다. 이전 페이지 로 전환하기 위해서는 손을 왼쪽에서 오른쪽으로 이동(평균 $23.3 \%$ )하고, 다음 페이지로 전환하기 위해서는 손을 오른쪽 에서 왼쪽으로 이동(평균 $22.2 \%$ )하는 제스처를 취하였다. 즉, 방향을 지시하는 정적 (Static) 제스처와 페이지를 넘기 듯 손을 이동시키는 동적(Dynamic) 제스처를 확인할 수 있었으며, Previous/next page 조작에 대해서 동적 제스처 에 비해 정적 제스처인 "방향 지시" 제스처의 빈도가 더 높 았다.

Volume up/down 조작에 대해서는 모든 기기에서 손을 "위/아래로 이동시키는" 제스처의 빈도가 가장 높았다. 많은 참여자들이 소리의 볼륨을 높이기 위해서 손을 위로 올리거
나(평균 $50.03 \%$ ), 볼륨을 줄이기 위해서 손을 아래로 내리 는 제스처(평균 $50.85 \%$ )를 취하였다. 이 외에도 평균 $10 \%$ 로 높은 빈도는 아니었지만 검지손가락을 시계 방향 또는 반 시계 방향으로 회전시키면서 볼륨을 조절하려는 제스처도 취하였다.

Zoom in/out 조작에 대해서는 모든 기기에서 양 손을 벌 리거나 한 손을 벌리는 제스처 빈도가 평균 $58.3 \%$ 로 가장 높았다. 이는 스마트폰과 같은 터치 기기에서 화면을 확대/ 축소하는 핀치 인-아웃(Pinch in-out) 조작방식과 동일한 제스처이다.

이 외의 단위 조작들에서는 낮은 빈도로 다양한 제스처들 을 볼 수 있었다. Power on/off 조작에 대해서는 모든 기기 에서 "화면 포인팅하기(평균 On $14.2 \%$, Off $12.5 \%$ )" 또는 "박수치기(평균 On $13.35 \%$, Off $12.5 \%$ )" 형태의 제스처를 볼 수 있었다. 특히 TV를 제외한 기기들에서는 엄지와 중지 손가락을 교차시켜 소리를 내는 "Finger snap" 제스처를 취 하여 기기의 전원을 켜거나 끄고자 하였다(평균 On $11.1 \%$, Off 8.9\%). 또한 전원을 켜기 위해 전원 아이콘과 유사한 형 태를 취하는 "동그라미 그리기" 제스처는 Navigation을 제 외한 기기들에서는 비교적 높은 빈도로 도출되었으며(평균 $16.7 \%)$, 전원을 끌 때는 헤어질 때 인사하듯이 "손을 흔들 거나" 손으로 기기의 화면을 위에서 아래로 쓸어 내리는 동 작인 "손 아래로 내리기" 제스처를 평균 10\% 빈도로 취하 였다.

Play 조작을 위해서는 기기 별 평균 $22.5 \%$ 가 "그리기" 형태의 제스처를 취하였다. 현재 화면을 선택한다는 의미로 동그라미를 그리거나, 재생 아이콘 형태인 삼각형을 그리는 제스처를 볼 수 있었다. 또한 터치 기기에서의 재생 시와 유 사하게 검지손가락으로 화면을 "포인팅"하는 제스처도 평균 $19.2 \%$ 의 빈도로 나타났다. 이 외에도 높은 빈도는 아니지만 Power on/off 조작에서 나타난 제스처들과 비슷한 형태의 "Finger snap"과 "박수치기" 제스처도 볼 수 있었다.

Cancel 조작은 양 손의 검지손가락을 교차하여 "X를 표 현"하거나, 손으로 "X 그리기" 형태의 제스처가 $26.67 \%$ 의 빈도로 나타났다. 또한 헤어질 때 인사하는 행동인 "손 흔들 기"와 "고개 흔들기" 제스처도 각각 평균 $17.5 \%, 10.85 \%$ 의 빈도로 나타났다.

Delete 조작을 위해서는 손으로 무언가를 잡아 던지거나 튕겨서 "버리는 제스처"가 평균 $32.5 \%$ 로 모든 기기에서 공 통적으로 가장 높은 빈도로 나타났다. Navigation을 제외한 기기들에서는 "양 손으로 종이를 구기는 듯한 제스처(평균 $15.6 \%)$ "를 취하여 삭제를 하고자 하였으며, Audio를 제외한 기기들에서는 양 손의 검지손가락을 교차하여 "X를 표현"하 는 제스처가 평균 $15.5 \%$ 의 빈도로 나타났다.

Search 조작을 위해서는 Search의 S를 쓰거나 물음표 
등의 "문자쓰기" 제스처가 네 종류의 기기에 대해 평균 $26.65 \%$ 로 나타났으며, 손을 머리에 갖다 대고 "생각하는 자세"를 취하는 제스처도 평균 $15.9 \%$ 의 빈도로 나타났다. 이외에도 검색 창을 의미하여 "양 손의 엄지, 검지손가락으 로 네모를 표현"하거나 검색 창을 부르는 의미로 누군가를 손으로 "부르는" 제스처도 나타났다.

Mute 조작에 대한 제스처는 "손으로 입 막는" 제스처(평 균 $25 \%$ ) 또는 "손으로 귀 막는" 제스처(평균 $23 \%$ ) 가 기기 마다 가장 높은 빈도로 나타났다. 이 외에도 "양 손바닥 모 으기", "주먹 쥐기" 제스처를 통해 소리를 없애고자 하였다.

Save 조작에는 다양한 제스처가 나타났다. Navigation을 제외한 기기들에서는 "양 손바닥을 모아" 손안에 현재 화면 을 저장하겠다는 의미의 제스처가 평균 $17.8 \%$ 빈도로 나타 났으며, 즐겨찾기 화면으로 저장하고자 한다는 의미로 "별 그리기" 형태의 제스처가 평균 $20 \%$ 빈도로 나타났다. 이외 에도 현재 화면을 가슴에 담는다는 의미로 "품에 가지고 오 는" 제스처(평균 $14.4 \%$ ) 도 나타났다. Computer를 제외한 기기들에서는 높은 빈도는 아니지만 엄지손가락을 올리는 "따봉" 제스처가 평균 $8.9 \%$ 로 나타났다.

연속 조작인 List up/down에서는 리스트이동 시 조작방식 에 대하여 사람들이 가지고 있는 심성모형 (Mental model) 이 서로 상충됨을 알 수 있었다. 상단부에 있는 리스트 항목 으로 이동하기 위해서 손을 "아래로 내리는" 제스처를 취한 참여자들은 스마트폰 조작방식처럼 위에 있는 목록을 보기 위해 아래로 화면을 내리는 제스처를 취했다고 응답하였다. 반면에 손을 "위로 올리는" 제스처를 취한 참여자들은 화면 에 있는 커서가 직접 위로 올라가서 위에 있는 목록으로 이 동하는 것을 생각하여 제스처를 취했다고 응답하였다. 각각 의 제스처는 평균 $25.8 \%$ 의 빈도로 비슷하게 나타났다.

\subsection{Types of derived gestures}

사람들이 취하는 제스처를 분류하는 기준은 연구들마다 다양하다(Pavlović et al., 1997; Nielsen et al., 2004; Karam \& Schraefel, 2005; Saffer, 2009). 본 연구에서는 여러 분류 기준을 종합하여 정리한 $\operatorname{Kim}(2012)$ 의 제스처

Table 3. Taxonomy of gestures in this study (Kim 2012)

\begin{tabular}{c|c|c}
\hline Shape & Static & Dynamic \\
\hline Deictic & & \\
\hline Semantic & & \\
\hline Manipulative & & \\
\hline Descriptive & & \\
\hline
\end{tabular}

분류 기준(Table 3)을 활용하여 도출된 제스처들을 분류하 였다(Table 3).

$\operatorname{Kim}$ (2012)는 제스처를 그 형태(Shape)와 움직임 (Motion)에 따라 2차원으로 분류하는 체계를 제안하였다. 형태는 크게 지시적(Deictic), 조작적 (Manipulative), 의미 적(Semantic), 묘사적(Descriptive) 제스처로, 움직임은 정 적(Static) 과 동적(Dynamic) 제스처로 분류하였다. 지시적 제스처는 손/손가락으로 명확하게 사물/대상을 가리키는 형 태이며, 조작적 제스처는 실제 사물을 인간이 다루는 것처럼 행동하는 형태이다. 의미적 제스처는 우리가 평상 시 의사소 통에 자주 사용하는 특정 의미를 나타내는 제스처이며, 묘사 적 제스처는 특정 사물이나 대상의 모양이나 움직임을 흉내 내는 제스처이다. 정적과 동적 제스처는 손가락이나 손의 정 적인 모양에 의한 표현인지, 동적인 움직임에 의한 표현인지 에 따라 구분된다.

기기의 구분 없이 4 종류의 기기에 대하여 10 명의 참여자 들이 3 번씩 취한 제스처를 Table 3 의 기준으로 분류한 결 과는 Figure 1 과 같았다(점선 바는 정적, 실선 바는 동적인 제스처를 나타냄). 전체적으로 정적인 제스처보다는 동적인 제스처가 많이 나타났다. 특히, 방향성을 갖거나 연속값을 갖는 단위조작들(i.e., Previous/next page, List up/down, Volume up/down, Zoom in/out)은 주로 동적인 조작적 제스처가 많이 나타났다. 반면, 일회성의 단위 조작들(i.e.,

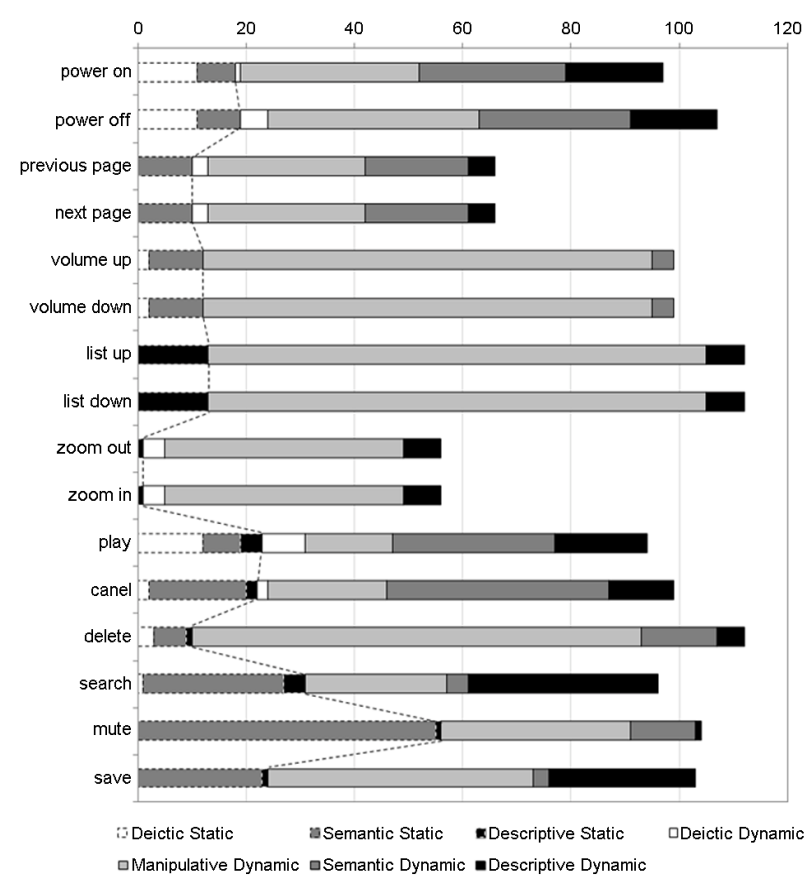

Figure 1. The number of derived gestures in terms of the taxonomy of gestures shown in Table 3 
Power on/off, Play, Cancel, Delete, Search, Mute, Save) 에서는 조작적 제스처도 많았으나 정적인 의미적 제스처가 상대적으로 많이 나타났으며, 동적인 의미적 제스처와 묘사 적 제스처도 많이 등장하였다. 지시적 제스처는 명확하게 지 시할 대상이 그려지는 경우(i.e., Power on/off, Play)에만 한정적으로 많이 나타났다. 하지만 Table 2 의 단위 조작 별 제스처 Agreement score와 비교해 보면 방향성을 갖거나 연속값을 갖는 단위 조작(i.e., Volume up/down, List up/ down, Zoom in/out) 은 평균값인 0.228 이상의 값을 가지 고 있었고, 일회성의 단위 조작(i.e., Play, Cancel, Search, Mute) 은 평균 이하의 값을 가졌다. 즉, 상/하/좌/우 방향에 따른 조작적 제스처와는 다르게 의미적/묘사적인 제스처는 다양한 의미를 부여할 수 있어 보다 다양한 종류의 제스처가 도출되었음을 알 수 있다.

\subsection{Subjective evaluation on gestures}

앞서 설명했듯이 실험 참여자들은 각 단위 조작에 대하여 3 가지씩의 제스처를 취한 후 각각의 제스처에 대하여 직관 성, 기억용이성, 동작편의성, 만족도를 5 점 척도로 각각 평 가하였다. 기기와 관계없이 각 조작 별 제스처들간의 직관성, 기억용이성, 동작편의성, 그리고 만족도 차이에 대한 유의확 률은 Table 4 와 같았다(데이터가 정규분포를 따르지 않아, Kruskal-wallis 비모수 검증을 이용하여 통계 검증하였음).

Volume up/down 조작은 제스처에 따라 만족도에 유의한 차이가 존재하였다 $(p=0.043)$. 볼륨조절을 위해 "시계/반 시계 방향으로 돌리기" 제스처의 만족도가 가장 높았으며, "귀에서 손을 가까이하기/멀리하기"와 "손 벌리기/모으기" 제스처의 만족도가 가장 낮았다(평균 4.54 vs. 3).

Zoom in/out에서는 만족도를 제외한 직관성 $(p=0.026)$, 기억용이성 $(p=0.035)$, 동작편의성 $(p=0.037)$ 에서 제스처 들 간에 유의한 차이가 존재하였다. 양 손 또는 한 손을 "벌 리기/모으기" 제스처의 직관성 점수가 가장 높았으며, 허공 을 연속 두 번 포인팅하는 "더블포인팅"과 "+/- 그리기" 제스처의 직관성 점수가 가장 낮았다(평균 5 vs. 3).

Play에 대해서는 기억용이성 $(p=0.032)$ 과 만족도 $(p=$ 0.029)에 제스처 별로 유의한 차이가 존재하였으며, 직관성 ( $p=0.064)$ 과 동작편의성 $(p=0.069)$ 에서도 약한 차이가 존재하였다. 기억용이성에 대해서는 엄지와 검지손가락을 동 그랗게 만든 형태의 "OK 표현" 제스처의 점수가 가장 높았 으며, Computer에서만 나타난 "주먹 쥐기" 제스처가 가장 점수가 낮았다(평균 4.71 vs. 2.33). 만족도도 "OK" 제스처 가 가장 높았으며, "주먹 쥐기", "박수 치기", "눈 깜박이기" 제스처에 대한 만족도가 가장 낮았다(평균 4.43 vs. 3). 직 관성과 동작편의성에 대해서도 "OK" 제스처가 각각 평균
Table 4. Results of nonparametric test on subjective evaluations to the derived gestures every operations ( $p$-value)

\begin{tabular}{c|c|c|c|c}
\hline Criteria & Intuitiveness & Memorability & Convenience & Satisfaction \\
Operations & & & & \\
\hline Power on & 0.285 & 0.071 & 0.558 & 0.481 \\
\hline Power off & 0.367 & 0.132 & 0.225 & 0.522 \\
\hline Previous page & 0.388 & 0.476 & 0.934 & 0.191 \\
\hline Next page & 0.388 & 0.476 & 0.934 & 0.191 \\
\hline Volume up & 0.784 & 0.083 & 0.157 & $\mathbf{0 . 0 4 3}^{*}$ \\
\hline Volume down & 0.784 & 0.083 & 0.157 & $\mathbf{0 . 0 4 3}^{*}$ \\
\hline List up & 0.600 & 0.202 & 0.608 & 0.458 \\
\hline List down & 0.600 & 0.202 & 0.608 & 0.458 \\
\hline Zoom out & $\mathbf{0 . 0 2 6}$ & $\mathbf{0 . 0 3 5}^{*}$ & $\mathbf{0 . 0 3 7 ^ { * }}$ & 0.193 \\
\hline Zoom in & $\mathbf{0 . 0 2 6}$ & $\mathbf{0 . 0 3 5}$ & $\mathbf{0 . 0 3 7 ^ { * }}$ & 0.193 \\
\hline Play & 0.064 & $\mathbf{0 . 0 3 2}^{*}$ & 0.069 & $\mathbf{0 . 0 2 9}{ }^{*}$ \\
\hline Cancel & 0.100 & $\mathbf{0 . 0 2 8}^{*}$ & 0.313 & 0.070 \\
\hline Delete & 0.337 & 0.516 & 0.367 & 0.136 \\
\hline Search & 0.089 & 0.433 & 0.145 & 0.195 \\
\hline Mute & $\mathbf{0 . 0 0 0}{ }^{* * *}$ & $\mathbf{0 . 0 0 2}^{* *}$ & $\mathbf{0 . 0 2 0}$ & $\mathbf{0 . 0 0 0}{ }^{* * *}$ \\
\hline Save & 0.250 & $\mathbf{0 . 0 0 6}^{*}$ & 0.186 & 0.206 \\
\hline & & & ${ }^{*} p<.05,{ }^{* *} p<.01,{ }^{* * *} p<.001$
\end{tabular}

4.86점, 4.57점으로 가장 높았으며, "주먹 쥐기" 제스처가 각각 평균 3점, 2.67점으로 가장 낮았다.

Cancel 조작의 제스처들에 대한 기억용이성 $(p=0.028)$ 평가점수에는 유의한 차이가 존재하였으며, 만족도 $(p=0.07)$ 는 유의하진 않았지만 약한 차이가 존재하였다. 양 손으로 "X를 표현"하는 제스처의 기억용이성(평균 4.68)과 만족도 가 가장 높았다(평균 4.06)

Mute 조작의 제스처들은 모든 면에서 유의한 차이가 존 재하였다. "입 막기" 제스처가 기억용이성 $(p=0.002)$, 동작 편의성 $(p=0.020)$, 만족도 $(p=0.000)$ 에 있어 점수가 가장 높았으며(각각 평균 4.6점, 4.5점, 4.5점), 직관성에 대해서 는 "입 막기"와 더불어 "귀 막기" 제스처도 점수가 높았다 (평균 4.57).

Save에 대해서는 기억용이성 $(p=0.006)$ 에 대해서만 제 스처들 간에 유의한 차이가 존재하여 "포인팅" 제스처와 Computer에서만 나타난 "손짓" 제스처의 점수가 가장 높았 다(평균 4.5점).

\subsection{Planning time}

실험 진행자가 단위 조작 태스크를 지시한 후, 참여자들 이 각 제스처를 취하는데 까지 걸린 구상시간(Planning time) 을 측정하였다. 이 시간이 짧을수록 더 빨리 해당 제스 
처를 떠올린 것이므로 해당 제스처가 사람들의 머리 속에 얼 마나 유효한가(Availability)를 나타낸다. 기기 별로 보면, 전반적으로 Audio에 대한 제스처를 취할 때 참여자들의 구 상시간이 가장 오래 걸렸고, TV에 대한 제스처를 취할 때 가장 짧게 걸렸다(평균 $24 \mathrm{~s}$ vs. $18 \mathrm{~s}$ ). 제스처들 간의 구 상시간은 Delete 조작에서는 유의한 차이가 존재하였으나 ( $p=0.029)$, Zoom in/out 조작에서는 약한 차이만 존재하 였다 $(p=0.068)$. Delete 조작에서는 "버리기" 제스처가 가 장 시간이 짧았으며, 손으로 "목을 치는 제스처"를 생각해내 는 시간이 가장 길었다(평균 $13 \mathrm{~s}$ vs. $44 \mathrm{~s}$ ). Zoom in/out 조 작에서는 양 손 또는 한 손을 "벌리거나 모으는" 제스처의 구상시간이 가장 짧았으며, 손을 "위로 올리거나/아래로 내 리기"를 통해 화면을 확대/축소하는 제스처의 시간이 가장 오래 걸렸다(평균 $12.94 \mathrm{~s}$ vs. $41.67 \mathrm{~s}$ ).

\section{Conclusion}

본 연구는 사용자 참여디자인의 방법으로 주요 기기 별 가장 기본적인 단위 조작들에 대해 적합한 비접촉 제스처를 도출하였다. 단위 조작 별 공통으로 나타나는 제스처를 바탕 으로 제스처 스테레오타입을 분석하고, 제스처의 빈도 및 참 여자들의 주관적 평가 그리고 제스처를 취하는데 걸린 구상 시간 등을 바탕으로 Table 5와 같이 제스처 어휘사전을 정 립하였다. Table 5 는 전체 제스처 사전 중 각 조작 별로 가 장 적합한 것으로 판단된 제스처들만 대표적으로 보여주고 있다. 비접촉 제스처에 기반한 인터랙션을 설계하고자 할 때 특정 조작에 적합한 제스처의 유형으로 어떤 것들이 가능한 지를 알고자 할 때 이러한 어휘사전은 유용하게 활용될 수 있을 것이다.

본 연구에서의 사용자 참여디자인 결과, 기기마다 나타나 는 제스처의 유형에는 큰 차이가 없었으나 정적보다는 동적 인 유형의 제스처가 많이 나타났으며 조작적 제스처가 많이 나타났다. 또한 단위 조작에 따라 나타나는 제스처의 유형에 큰 차이가 존재하였다. 연속적인 단위 조작(i.e., Previous/ next page, List up/down, Volume up/down, Zoom in/out) 은 물리적 조작방법에 따른 조작적 제스처 (Manipulative gesture)가 주로 나타났다. 반면 일회성의 단위 조작(i.e., Power on/off, Play, Cancel, Delete, Search, Mute, Save) 은 이미 알려진 의미적인 모양을 취하는 의미적 제스처 (Semantic gesture) 또는 정보를 쓰거나 그려서 표현하는 묘사적 제스처(Descriptive gesture) 가 많이 나타났다. Choi et al. (2012)에서도 이와 유사한 연구 결과가 나왔다. 또한 Agreement scores를 살펴보면 연속적인 단위 조작에 대한
제스처의 의견 일치 정도가 일회성의 단위 조작에 비해 높다 는 것을 알 수 있었다(Table 2). 이는 상/하/좌/우 방향에 대해서만 제스처를 취하는 연속적인 조작적 제스처에 비해 일회성의 의미적/묘사적 제스처는 참여자마다 다양한 모양을 떠올렸기 때문이다.

본 연구를 통해 도출된 제스처 사전은 향후 비접촉 제스처 에 기반한 인터랙션을 디자인하거나 표준 제스처를 정립하 기 위한 기초자료로 활용될 것으로 기대한다. 그러나 본 연 구는 다양한 연령층 및 문화에 따른 차이를 고려하지 않았 고 20 30대의 한국인만을 대상으로 했다는 한계를 가지고 있다. 사용자들의 제스처에 대한 심성모형 (Mental model)은 연령, 문화적 차이, 직업, 라이프 스타일 등에 의해 영향을 받을 수 있기 때문에 향후 참여자의 범위를 확대하여 추가 조사를 할 필요성이 남아 있다. 무엇보다도, 본 연구에서 도 출된 제스처들을 실제 사용 환경에 적용 가능한지에 대한 추가 검증이 필요하다. 또한 본 실험은 실제 제품을 사용하 는 상황에서 수행된 것이 아니라 아무 것도 보여주지 않고 참여자의 상상 속 기기를 제스처로 조작하도록 하였다. 그러 나 정적인 상황에서 생각해낸 제스처와 실제 동적인 상황에 서 적용 가능한 제스처는 다를 수 있다. 예를 들면, 스마트 폰에 흔히 사용하는 터치 제스처 조작인 Flicking, Panning, Pinching 중에서 Pinching 조작은 자동차가 정차 중 일 때 는 가능한 조작이지만, 운전 중 일 때에는 높은 시각주의 (Visual attention)를 요구하여 안전상의 이유로 위험한 조 작일 수 있다(Kim \& Song 2012). 이처럼 같은 제스처 조 작일지라도 조작상황에 따라 적용 가능 여부가 달라질 수 있기 때문에 이를 검증하여 실제 상황에서도 응용 가능한 명 확한 제스처 가이드를 제시할 필요성이 있다.

Table 5. Established gesture dictionary from the experimental results

\begin{tabular}{|c|c|c|c|c|}
\hline Operations & \multicolumn{4}{|c|}{ Gestures } \\
\hline \multicolumn{5}{|l|}{$\begin{array}{c}\text { Power } \\
\text { on }\end{array}$} \\
\hline & Pointing & Clapping & Finger snap & $\begin{array}{c}\text { Drawing a } \\
\text { circle }\end{array}$ \\
\hline \multirow[t]{2}{*}{$\begin{array}{c}\text { Power } \\
\text { off }\end{array}$} & & & & $\dot{v}$ \\
\hline & Clapping & Pointing & Finger snap & Lower hand \\
\hline
\end{tabular}


Table 5. Established gesture dictionary from the experimental results (Continued)

Operations
$\begin{gathered}\text { Previous } \\ \text { page }\end{gathered}$

Table 5. Established gesture dictionary from the experimental results (Continued)

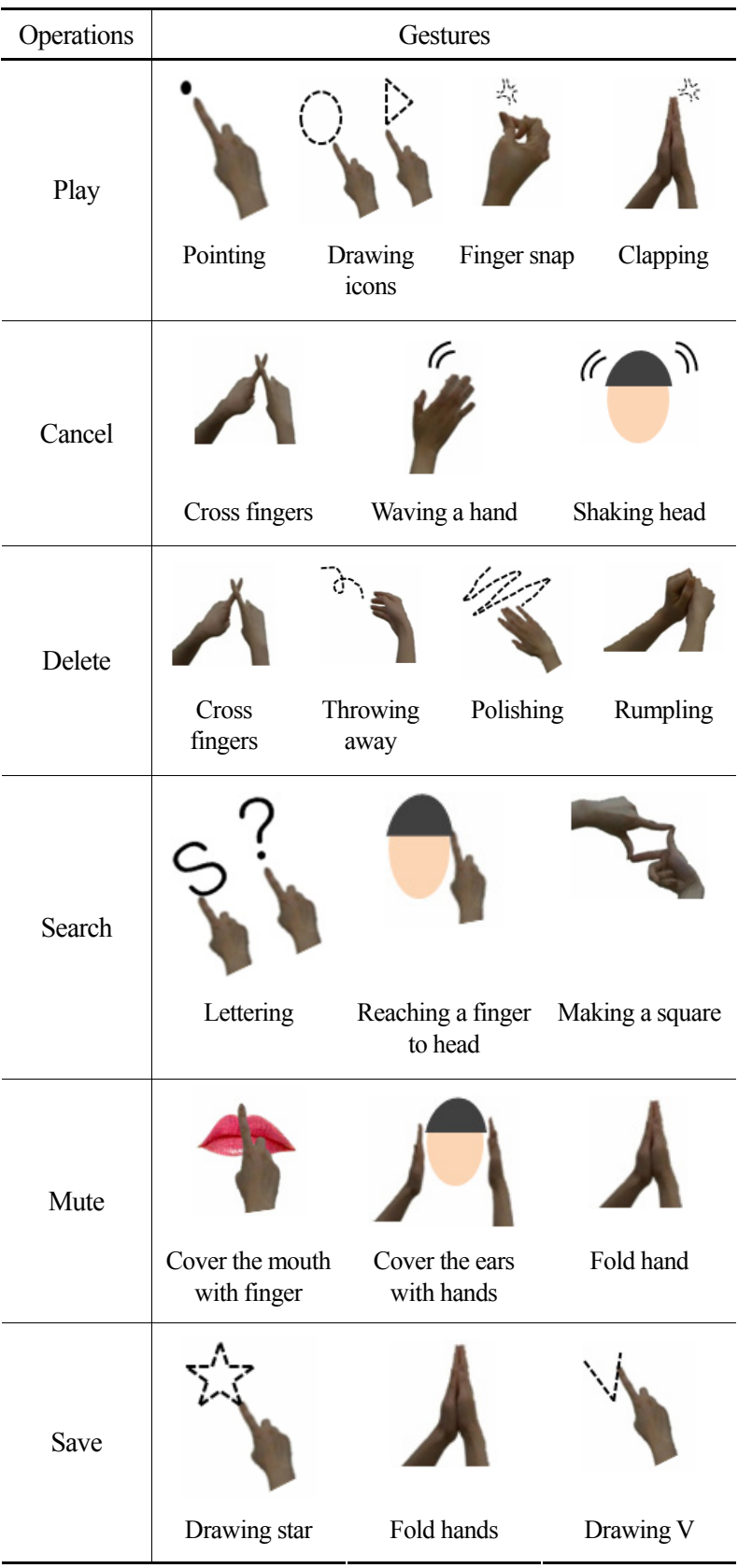

\section{Acknowledgements}

This study was partially supported by Seoul National University of Science and Technology. 


\section{References}

Cho, S. I., Hong S. Y., Hong, J. Y., Yang, K. I., Jang, G. Y. and Choi, J. H., Study on Input Method of Smart TV Depending on Operation Command, HCI 2012, 631-634, 2012.

Epps, J., Lichman, S. and Wu, M., A Study of Hand Shape Use in Tabletop Gesture Interaction, CHI Conference on Human Factors in Computing Systems, 748-753, Montreal, Quebec, Canada, April 22-27, 2006.

Helman, I. S., Jane, P. W. and Yael, E., Optimal Consensus Intuitive Hand Gesture Vocabulary Design, IEEE International Conference on Semantic Computing, 96-103, 2008.

Hummels, C. and Stapers, P. J., Meaningful Gestures for Human Computer Interaction: Beyond Hand Postures, Proceeding of the 3rd International Conference on Automatic Face \& Gesture Recognition, 591-596, Nara, Japan, April 14-16.IEEE Computer Society Press, Los Alamitos, CA. 1998.

Jaime, R., Yang. L. and Edward, L., User-defined Motion Gesture for Mobile Interaction, CHI'11 Proceedings of the 2011 Annual Conference on Human Factors in Computing Systems, Vancouver, BC, Canada, 2011.

Karam, M. and Schraefel, M. C., A Taxonomy of Gestures in Human Computer Interaction, Technical Report ECSTR-IAM05-009, Electronics and Computer science, University of Southampton, 2005.

Kim, D. H. and Kim, D. J., An Intelligent Smart Home Control Using Body Gestures, In the Proceedings of International Conference on Hybrid Information Technology, IEEE. Korea. 2006.

Kim, D. H., Cho, S. H., Cheon, Y, J. and Kim, D. J., A Hand Gesture Recognition Method for An Intelligent Smart Home TV Remote Control System, Korean Institute of Information Science and Engineers. vol. 34, No. 2(C), 2007.

Kim, H., Interacting with Touchless Gestures: Taxonomy and Requirements, Journal of the Ergonomics Society of Korea, This volume, 2012.

Kim, H. and Song, H. W., The Safety Usability of Operating In-Vehicle Information System with Touch Gesture, Applied Ergonomics, To be appeared in 2012.

Kim, H. S., Hwang, S. W. and Moon, H. J., A Study on Vision Based Gesture Recognition Interface Design for Digital TV, Journal of Korean Society of Design Science, Vol. 20, No. 3, 257-268, 2007.

Kray, C., Nesitt, D, Dawson, J. and Rohs, M., User-Defined Gestures for Connecting Mobile Phone, Public Display, and Table Tops, In Proceeding Mobile HCI, 239-248, 2010.

Lee, S., Kim, S., Jin, B., Choi, E., Kim, B., Jia, X., Kim, D. and Lee, K., How Users Manipulate Deformable Displays as Input Devices, $\mathrm{CHI}$ 2010, pp.1647-1656, April 10-15, Atlanta, GA, USA, 2010.

Morris, M., Wobbrock, J. and Wilson, A., Understanding Users Preferences for surface gestures, In Proceeding GI, pp. 261-268, Canadian Information Processing Society, 2010.

Nielsen, M. Störring, M., Moeslund, T. B. and Granum, E., A Procedure for Developing Intuitive and Ergonomic Gesture Interface for HCI,
In: Gesture-Based Communication in Human-Computer Interaction, 105-106, 2004.

Pavlović, I. V., Sharna, R. and Huang, S. T., Visual Interpretation of Hand Gestures for Human-Computer Interaction, IEEE Transactions on Patiern Analysis and Machine Intelligence, Vol. 19, No. 7, 1997.

Saffer, D., Designing Gestural Interfaces, O'Reilly Media, Inc., 2009.

Song, H. W., Establishing a Design Guide of Gestures for Touchless Interactions, Unpublished Master's Thesis in Seoul National University of Science and Technology, 2012.

Stößel, C., Familiarity as a factor in designing finger gestures for elderly users, Mobile HCI'09, Bonn, Germany, September 15-18, 2009.

Stößel, C. and Blessing, L., Mobil Device Interaction Gestures for Older Users, Nordi CHI, Reykjavik, Iceland, October 16-20, 2010.

Wigdor, D. and Wixon, D., Brave NUI World, Morgan Kaufmann, 2011.

Wobbrock, J. O., Morris, M. R. and Wilson, A. D., User-defined Gestures for Surface Computing, In Pros, CHI, ACM Press, 1083-1092, 2009.

\section{Author listings}

\section{Haewon Song: song87@seoultech.ac.kr}

Highest degree: Master Degree, Department of Product Design and Manufacturing Engineering, Seoul National University of Science and Technology

Position title: Graduate Student, Graduate School of NID Fusion Technology, Seoul National University of Science and Technology Areas of interest: Human Factors, HCI, Interaction Design

\section{Huhn Kim: huhnkim@seoultech.ac.kr}

Highest degree: $\mathrm{PhD}$, Department of Industrial Engineering, KAIST Position title: Professor, Department of Mechanical System Design Engineering, Seoul National University of Science and Technology Areas of interest: Human Factors in Product Design, HCI, User Experience Design

Date Received : 2012-07-14

Date Revised :2012-07-30

Date Accepted : 2012-07-30 